\title{
EDUCAÇÃO COMO DIREITO FUNDAMENTAL: PAREDES DE COURA - UMA EXPERIÊNCIA PORTUGUESA DESTACA “A DESCOBERTA DO SER CRIANÇA NO MEIO RURAL"
}

\section{Education as a fundamental right: Paredes de Coura - a portuguese experience highlights "the discovery of being a child in rural areas"}

\section{La educación como derecho fundamental: Paredes de Coura - una experiencia portuguesa destaca "el descubrimiento de ser niño en las zonas rurales"}

\author{
António Cardoso Ferreira* \\ Maria José Dias Ferreira** \\ Maria Edith Romano Siems ${ }^{* * *}$
}

\begin{abstract}
Resumo
O presente artigo apresenta um estudo de caso em que se descrevem e analisam ações comunitárias em educação e saúde, realizadas em uma região rural portuguesa, na década de 1980 e na qual se observa o impacto dos conceitos e ideias desenvolvidas por Paulo Freire. Conceitos freireanos como o de conscientização, fundamentaram a condução das atividades de um conjunto de profissionais de saúde pública, que atuavam junto a populações em situação de vulnerabilidade social, com o intuito de melhoria de sua qualidade de vida, enfatizando suas potencialidades de auto desenvolvimento em ações comunitárias. O relato aqui apresentado insere-se no conjunto dos estudos que tratam da circulação de ideias e saberes pedagógicos entre diferentes grupos culturais e de como essa circulação é ressignificada e apropriada de maneiras diversas em diferentes espaços e tempos. A estrutura narrativa adotada assumindo, em seus processos descritivos e analíticos, as vozes de diferentes profissionais em seus pontos de vista e percepções traz a polissemia das vivencias de uma equipe multiprofissional na execução de um processo em que ao tempo em que constituiu-se a força de uma organização comunitária, também profissionais se constituíram em agentes de transformação social.
\end{abstract}

PALAVRAS-CHAVE: Direitos Humanos. Conscientização. Paulo Freire. Educação Comunitária.

\footnotetext{
Abstract

This article presents a case study describing and analyzing community actions in education and health, carried out in a rural Portuguese region, in the 1980s and in which the impact of the

* Médico com Especialização em Saúde Pública. Endereço: Rua da Ribeira, 15. 6120-019. Ladeira. Envendos. Portugal. E-mail: mjose7777@ sapo.pt.

** Médica com Especialização em Saúde Pública. Endereço: Rua da Ribeira, 15. 6120-019. Ladeira. Envendos. Portugal. E-mail: mjose7777@ sapo.pt

*** Doutora em Educação Especial pela Universidade Federal de São Carlos. Professora do Centro de Educação da Universidade Federal de Roraima. Endereço profissional: Avenida Capitão Ene Garcez, 2413, Aeroporto, 69310-000, Boa vista/Roraima - Brasil. Contato profissional: (95) 36213102. E-mail: edith.romano@ufrr.br Orcid: https://orcid.org/0000-0001-5527-0065
} 
concepts and ideas developed by Paulo Freire is observed. Freirean concepts such as awareness, underpinned the conduct of the activities of a group of public health professionals, who worked with populations in situations of social vulnerability, with the aim of improving their quality of life, emphasizing their potential for self development in community actions. The report presented here is part of the set of studies that deal with the circulation of ideas and pedagogical knowledge between different cultural groups and how this circulation is reframed and appropriated in different ways in different spaces and times. The narrative structure adopted assuming, in their descriptive and analytical processes, the voices of different professionals in their points of view and perceptions brings the polysemy of the experiences of a multiprofessional team in the execution of a process in which at the time the force of a community organization, also professionals became agents of social transformation.

KEYWORDS: Human Rights. Awareness. Paulo Freire. Community Education.

\section{Resumen}

Este artículo presenta un estudio de caso que describe y analiza las acciones comunitarias en educación y salud, realizadas en una región rural portuguesa, en la década de 1980 y en el que se observa el impacto de los conceptos e ideas desarrollados por Paulo Freire. Conceptos freireanos como conciencia, sustentaron la conducción de las actividades de un grupo de profesionales de la salud pública, que trabajaron con poblaciones en situación de vulnerabilidad social, con el objetivo de mejorar su calidad de vida, enfatizando su potencial de autodesarrollo en acciones comunitarias. El informe que aquí se presenta forma parte del conjunto de estudios que abordan la circulación de ideas y conocimientos pedagógicos entre diferentes grupos culturales y cómo esta circulación se replantea y apropia de diferentes formas en diferentes espacios y tiempos. La estructura narrativa adoptada asumiendo, en sus procesos descriptivos y analíticos, las voces de diferentes profesionales en sus puntos de vista y percepciones trae la polisemia de las experiencias de un equipo multiprofesional en la ejecución de un proceso en el que en su momento la fuerza de una organización comunitaria, también los profesionales se convirtieron en agentes de transformación social.

PALABRAS CLAVE: Derechos humanos. Conciencia. Paulo Freire. Educación comunitaria.

\section{INTRODUÇÃO}

A circulação de ideias, saberes e conhecimentos construídos pelas sociedades humanas mostra-se elemento fundamental para o desenvolvimento de grupos sociais e culturais em suas práticas, em suas articulações e no que podem trazer de enriquecedor à vida da coletividade.

Mikhail Bakhtin, o potente pensador e filósofo russo que ao longo do século XX nos trouxe tantas e tão importantes contribuições para pensar as relações com a alteridade, com a linguagem que nos constitui enquanto seres de ação e diálogo, nos coloca a refletir sobre a responsabilidade de nossos atos e da responsividade em que eles se inserem (BAKHTIN, 2012).

Em perspectiva semelhante e salientando o papel de todos e de cada um na construção de sociedades humanas em que a justiça social se instaure e a tomar por base a lógica de que os seres humanos "se educam em comunhão", é que apresentamos o 
presente trabalho, pautados na relevância dos saberes de todos e de que estes sejam ampla e profundamente partilhados como nos ensina Paulo Freire.

O contato com a experiência de ação aqui relatada, deu-se no âmbito de uma pesquisa cujo objetivo era compreender impactos do pensamento pedagógico produzido por autores brasileiros na formação de professores em Portugal. Entretanto, no decorrer da pesquisa, nos deparamos com a forte e vívida circulação de referenciais freireanos em ações que se estenderam para muito além da educação formal ou da tradicionalmente citada metodologia de alfabetização de adultos, com impactos que se colocam acima e além da reflexão sobre práticas educativas e procedimentos didáticopedagógicos, para um conjunto de ações que se instauram no âmbito do filosófico, enquanto formas de ser e estar no mundo.

O presente relato, que se constitui em relevante estudo de caso, nos foi apresentado por dois profissionais da área médica que nos anos 1967 e 1968, período em que decorria sua formação universitária, tiveram contato com processos de alfabetização de adultos e de animação sociocultural desenvolvidos com base na metodologia de Paulo Freire, replicando, com as necessárias adequações, a experiência de Angicos (Pernambuco, Brasil) em zonas rurais portuguesas, destacadamente Portalegre e Coimbra, em ações articuladas pelo Movimento Graal. Um destes, então estudante e hoje médico aposentado, atuou voluntariamente como alfabetizador, reconhecido por participantes do projeto como referência, em decorrência da qualidade de sua ação.

Neste artigo, apresentamos em forma de relato que apresenta as diferentes vozes dos envolvidos no caso em estudo, elementos reflexivos sobre o percurso concreto da vida que sustentou os primeiros anos do OUSAM - Organismo Utilitário e Social de Apoio Mútuo e do Projeto "A Descoberta do Ser Criança no Meio Rural”, com o intuito de contribuir para reavivar memórias através da narrativa, o que deve passar também por fazer circular esta forma de energia que está nas entrelinhas do que se escreve e que é essencial para o ânimo e a ação de tudo o que queira revitalizar pessoas e comunidades.

O documento "Paredes de Coura - OUSAM e o Projeto "A Descoberta do Ser Criança no Meio Rural", foi inicialmente redigido em 2012, com elementos que projetavam a realização de um encontro ficcional, até então apenas imaginado e enviado à Direção do OUSAM e a alguns dos intervenientes no Projeto. Posteriormente, a Direção do OUSAM tomou-o como referência para promover um encontro, em Paredes de Coura, juntando as pessoas que atualmente mantêm as diversas atividades que a Associação realiza no concelho, com muitas das que anteriormente se relacionaram com o OUSAM.

Este encontro ocorreu em março de 2014, iniciou com uma visita guiada às instalações onde o OUSAM presta serviços a grupos de idosos e crianças do concelho, e culminou com uma reunião em que participaram mais de 40 pessoas, partilhando memórias, analisando o presente e perspetivando o futuro. Neste perspectivar o futuro, questões como o envelhecimento da população e as alterações nas relações institucionais se destacam, entretanto, entendemos que dar a conhecer o trabalho desenvolvido pode, para além de efetivar um relevante registro histórico, inspirar ações em outras coletividades.

A elaboração do texto parte de ideias registadas nos planos de atividades e nos relatórios de avaliação, mas é também enriquecida com memórias de conversas e reuniões em que o primeiro autor desta reportagem imaginada participou ao longo de 
vários anos. Optou-se por projetar em narrativa a encenação de um encontro ficcional que desse dinamicidade e permitisse que se desse vazão à mistura de leituras de textos com o reviver de experiências acontecidas há vinte e muitos anos.

Como se poderá observar ao longo da narrativa, emerge em muitos passos o entendimento de que as ações realizadas devam decorrer do profundo conhecimento das comunidades interessadas, não apenas em seu perfil sócio-econômico e cultural, mas também o destaque dado ao papel do diálogo horizontal entre todos os envolvidos para que se possa avançar na construção de ações cujos efeitos sejam palpáveis.

Nessa forma de ação identificamos, em muitos momentos, a influência do pensamento freireano, não enquanto teorização referenciada, mas enquanto modo de condução prática das ações, na valorização de uma horizontalidade de saberes, em uma construção coletiva demarcada pela dialogicidade, pelo protagonismo partilhado e pelo empenho na construção de bases de autonomia e empoderamento das comunidades, elementos presentes em Freire ( 1967 e 1974).

\section{O encontro}

Estamos todos espalhados por aquela sala enorme com paredes de granito e uma grande parede-porta totalmente envidraçada que comunica com o verde do pasto, das árvores e da Montanha. É uma manhã de névoa e chuva miudinha, a tornar a montanha apenas num vulto de contornos esbatidos e a fazer parecer, pela proximidade da neblina, que o céu está quase ao nosso alcance.

Juntámo-nos para recordar e debater algo que se passou em Paredes de Coura na década de oitenta, ou melhor, como é que cada um de nós tocou e foi tocado por aquilo que nos reúne hoje - um projeto designado "À descoberta do ser criança no meio rural", promovido por uma associação com a sigla OUSAM - Organismo Utilitário e Social de Apoio Mútuo. A razão do encontro pode parecer estranha porque não se trata de um Seminário com intervenções estruturadas nem de um estudo formal académico, com circulação de questionários escritos para respostas a integrar em códigos, de modo a serem depois classificadas e comparadas.

Não, já disse que estamos espalhados por ali, uns de pé, outros em cadeiras ou sofás, outros ainda sentados nos dois degraus que atravessam a sala e que temos de descer quando queremos chegar à grande parede envidraçada que se abre para o verde $\mathrm{e}$ para a neblina da manhã.

É verdade que antes tinha havido algumas conversas incompletas recordando o Projeto e o que dele se prolongou depois até quase hoje.Mas ninguém nos convocou por escrito, não houve uma Comissão, uma carta, um anúncio nos jornais da terra, a marcar este encontro. Apenas combinámos, trocámos mensagens, e- mails, chamadas telefónicas, conversas de esquina, e chegámos aqui entre as oito e as nove da manhã, descemos uma rua estreita de empedrado irregular, abrimos um portão largo, reparámos nos coelhos engaiolados e nos gansos à solta, entrámos na casa, distribuímos abraços e cumprimentos, bebemos um café, comemos uns biscoitos de milho e sentámo-nos à espera de começar.

Alguns de nós continuam a viver por aqui, outros afastaram-se para o Porto ou mais para o sul, outros ainda emigraram como antes já acontecera. E há também os que já viajaram para além da neblina que parece mostrar o céu quase ao nosso alcance... 
Nem sequer nos conhecemos todos uns aos outros...Há educadoras de infância, professores e assistentes sociais que aqui estiveram alguns anos na década de oitenta ou de noventa, outras educadoras que vieram já depois de 2000; há gente que passou pela direção do OUSAM em diferentes épocas, há pessoas do Centro de Saúde, dos Bombeiros, de Juntas de Freguesia, da Câmara e até alguns párocos que em determinado período foram também protagonistas desta dança; há quem tenha sido motorista das carrinhas, tenha trabalhado na área administrativa do OUSAM, tenha cozinhado nas cantinas...

Há ainda aqui na sala umas tantas pessoas que entraram no Projeto quando eram crianças e outras que se lhe juntaram por causa dos filhos ou netos. À sua maneira, também elas pegaram nas atividades e propostas e participaram no B-A-BÁ da Descoberta de cada dia.

Foram portanto gente que se cruzou e muito variados os caminhos pelos quais cada um ou cada uma se encontrou com o Projeto, mas o que nos fez vir hoje aqui foi o facto de todos sentirmos que o Projeto é um bocadinho nosso e que ao mesmo tempo ele se fez com todos nós e com muita gente mais.

Vemos que se ergue agora aquele que foi o primeiro Presidente da Direção do OUSAM"Caros amigos e amigas! Sabemos que o OUSAM se constituiu e formalizou em 1985, e que nesse mesmo ano se iniciou o Projeto "À descoberta do ser criança no meio rural", promovido por esta Associação como contributo para a prevenção do insucesso escolar no concelho de Paredes de Coura. Ora uma pergunta que me fazem muitas vezes é esta: - O que é que se passou em Paredes de Coura para que em 1985 se criasse o OUSAM e se arrancasse logo com este Projeto? Qual a origem de tudo isto?Já que estamos aqui para juntar as peças do puzzle das nossas memórias em relação ao nascimento do OUSAM e do Projeto "À descoberta do ser criança no meio rural", penso que será bom começarmos por aqui. E acrescento, para já, que, em minha opinião, muitas coisas se juntaram para que em 1985 se dessem estes dois acontecimentos. E talvez isso nos obrigue a recuar até aos fins de 1981, quando uma enfermeira e uma médica, aqui presentes, se mudaram para esta terra e vieram trabalhar para o Centro de Saúde".

Levanta-se então a enfermeira: "Não sei bem como é que se pode relacionar a nossa vinda para Paredes de Coura com o que veio a suceder quatro anos depois... Mas posso contar-vos alguma coisa sobre esses primeiros tempos e vocês verão. Nós viemos em novembro de 1981. Já tínhamos trabalhado juntas durante algum tempo, no Alentejo, e viemos mesmo à descoberta do que era a vida por estas bandas. Eu não fazia a mínima ideia onde era Paredes de Coura... e o primeiro ano foi o de ir aprendendo a conhecer, passo a passo, uma realidade diferente, olhando-a como pessoa mas também como técnica de saúde. É que, para se trabalhar na comunidade e com a comunidade, precisamos de ir identificando quais são as necessidades, as expectativas e as motivações das pessoas, e encontrar maneira de equacioná-las e devolvê-las. Ora, isto precisa de tempo para conseguirmos entrar, comunicar e entender como vivem as pessoas e o que move as suas vidas.Lembro-me, por exemplo, que naquele tempo, perto de metade dos partos aconteciam em casa, sem assistência de médico ou parteira. E sabíamos que isso afetava a taxa de mortalidade materna e perinatal, bem como a proporção de crianças com deficiências, como mais tarde viemos a confirmar; mas então, o que era preciso aprofundar era os porquês em relação a haver tantas mulheres que nunca iam a uma consulta durante a gravidez e tinham o parto em casa e como é que poderia alterar-se esta situação. Ora para isso tinha de se partir de conversas em que havia mulheres que nos diziam mais ou menos isto: 'Quero ter o meu filho em casa. Já 
tive outro assim e tudo correu bem, graças a Deus. A maternidade é muito longe, fica-se dentro de paredes desconhecidas, as visitas só podem entrar a certas horas e têm que pagar as viagens; a gente não se sente à vontade...' Foram frases como estas que escutámos várias vezes nesta primeira fase".

"Também nos pusemos as duas, juntamente com as outras enfermeiras, a lançar as bases para um programa sistemático de Saúde Escolar e isso levou-nos a visitar todas as escolas, a conversar com os professores e perceber, por exemplo, a extensão das caminhadas que algumas crianças tinham que fazer todos os dias.Lembro-me também que ficámos então a conhecer dois professores que já iam às vezes ao Centro de Saúde pedir materiais para trabalhar com as crianças certos assuntos, e que, talvez não por coincidência, vieram depois a ter um papel importante no OUSAM e no Projeto.O primeiro ano foi assim, de envolvimento conjunto em diversas coisas e com diversas pessoas, a ouvir antes de dizer... Mas do que é que tu te lembras mais?"

A interpelada era a médica, que tinha vindo também em Novembro de 1981:"Estava a pensar agora em como foi fácil aos meus filhos integrarem-se com as outras crianças do bairro onde ficámos a viver e como eles se divertiam com o sotaque minhoto e as palavras novas que aprendiam... Mas nesse primeiro ano, a minha principal aventura foi a luta pela integração total dos serviços de saúde no edifício do hospital concelhio que estava a ser restaurado e só ficou pronto mesmo no fim de 1982. Quando chegámos, o Centro de Saúde, os Serviços Médico-Sociais da Caixa de Previdência e a Urgência funcionavam em locais diferentes, todos acanhados, e não estava a funcionar o serviço de internamento enquanto se aguardava a conclusão das obras. E havia aquele grande edifício a ser recuperado, destinado a voltar a ser apenas um hospital concelhio. No entanto, os serviços já estavam então todos integrados formalmente com uma mesma Comissão Instaladora, que fiquei a presidir, por ser médica de saúde pública".

"Ora, quando visitei as obras do hospital concelhio, vi que ali cabíamos todos, e que podia manter-se um internamento, embora mais pequeno, e até uma pequena maternidade. Aliás, os responsáveis distritais apoiaram a minha proposta, até porque o hospital concelhio tinha demasiadas camas face às necessidades do concelho. O que foi mais complicado foi a resistência que alguns médicos fizeram a esta iniciativa, assim como outros profissionais que estavam muito ligados às suas rotinas e ao pequeno grupo de colegas com quem conviviam, e de alguns autarcas que achavam que esta proposta levava a uma perda de visibilidade dos serviços de saúde do concelho.Felizmente, o bom senso e a novidade da integração dos serviços acabaram por prevalecer e mesmo no princípio de 1983, mudámos todos para a nova casa. A própria mudança ajudou à cooperação mais alargada entre os que vinham de casas diferentes. E depois, aos poucos, a equipa alargou-se e revelaram-se até os talentos de alguns em novas funções de que gostavam... e todos começámos a ver que agora a comunicação entre a Urgência, as consultas, o internamento, as vacinas e a parte administrativa era muito mais fácil.Pensando agora na relação que tudo isto possa ter com o OUSAM, estou-me a lembrar do grupo que ia fazer um intervalinho no café onde conversavam sobre tantas coisas que até talvez tenha sido aí que começou a germinar a ideia de se criar uma associação..."

No meio dos risos que então se ouviram, uma voz soou mais alto:"Mas ainda não se falou no terceiro elemento deste trio de intrusos. Ora diga lá coisas, senhor delegado de saúde!" 
Os olhares viraram-se para alguém, que não se fez rogado e começou a falar: "Eu só consegui vir para Paredes de Coura em Outubro de 1982. Vinha de um período de grande sobrecarga de trabalho e irritava-me ver que naquelas primeiras semanas não tinha quase nada para fazer, pois as tarefas estavam já todas distribuídas... Mergulhei então a fundo na recolha de todos os dados possíveis para se caraterizar o concelho e identificar os principais problemas relacionados com a saúde, a fim de se preparar um primeiro plano de atividades. Este trabalho prolongou-se aliás por todo o ano de 1983, entremeado com apoios às urgências, idas às escolas, e, a partir de certa altura, o trabalho no posto de saúde recém-criado em Rubiães, para apoio às famílias de três ou quatro freguesias ali à volta, em que as consultas se completavam com idas a casa de algumas pessoas muito dependentes. Esta experiência do posto de Rubiães e dos apoios domiciliários constituiu aliás uma aprendizagem muito importante sobre as condições de vida, a cultura, as dificuldades de deslocação de lugar para lugar, e os problemas de saúde de muitas famílias, desde as crianças aos idosos, entre o desamparo e a dependência, as feiras e as festas, as mezinhas e as benzeduras, os direitos não respeitados e o precisar de pagar todos os favores..."

No curto silêncio que se seguiu a estas palavras, uma professora, já reformada, diz: "Voltando ainda ao tal primeiro plano de atividades, recordo-me agora de uma reunião com professores para discutirmos e "votarmos" uma lista de problemas de saúde...".

O médico aproveita a "deixa” para explicar:"É verdade! De facto, a nossa caraterização do concelho e identificação de problemas de saúde levou a uma lista de treze situações, e partimos daí para reuniões com os vários setores do Centro de Saúde e também com professores, párocos e autarcas, além da própria Comissão Consultiva de Saúde. Nessas reuniões, realizadas em fins de 1983, houve discussão sobre a lista de problemas apresentada e no fim cada um votou nos que considerava mais importantes, com base em critérios de prioridade (extensão, gravidade e frequência dos problemas; meios para lhes dar resposta; grau de motivação da população para aderir às medidas necessárias).Resultaram sete prioridades com base nas quais se apresentou depois o Plano de Atividades para 1984, pedindo-se a colaboração de todos na sua realização e avaliação".

"Então, e o tal problema do Insucesso Escolar já estava entre essas sete prioridades escolhidas?" - perguntou uma educadora de infância que tinha participado no Projeto já muito mais tarde. Ao que se responde: "Não, ainda não estava. E nisso há algo de interessante. A recolha de dados que levou à identificação de problemas incluiu os dados obtidos a partir das nossas conversas com os professores, além de dados referentes às consultas das crianças e adolescentes, e de outros elementos estatísticos a que tivemos acesso. Ora, talvez nem os professores nem os técnicos de saúde estivessem a pensar no insucesso escolar enquanto problema relacionável com a saúde... Ou, talvez também, pudesse estar "banalizado" o facto de ser habitual o insucesso escolar, a par de uma taxa elevada de analfabetismo na população. Assim, entre os treze principais problemas de saúde inicialmente identificados, os que tinham relação mais direta com as crianças foram "elevado número de crianças deficientes", "elevado número de parasitoses em crianças das escolas primárias", "elevado número de crianças com cárie dentária", "alimentação deficiente em proteínas e vitaminas" e "aquisição de hábitos de consumo de bebidas alcoólicas em número elevado de crianças com menos de catorze anos". Destes cinco, só os três primeiros entraram depois nas sete prioridades escolhidas." 
"Também posso acrescentar que me recordo que foi depois no ano de 1984 que se começou a conversar sobre o insucesso escolar entre técnicos de saúde e professores, até a propósito das medidas que foram sendo implementadas em relação aos problemas que tinham sido considerados prioritários. Por exemplo, lembro-me que se encontrou um número elevado de crianças sem deficiências mas com grandes dificuldades de aprendizagem e óbvio insucesso escolar."

Mas tudo o que se está agora a falar mostra-nos que nos faz falta ouvir outra pessoa que começou por nos visitar em fins de 1983, e depois voltou no início de 1985 e acabou por ficar cerca de quatro anos. É aquela educadora de infância que, antes de todos nós, sonhou com as linhas mestras do que veio depois a ser o Projeto "Á descoberta do ser criança no meio rural" e cuja energia nos empurrou para a concretização destas ideias. Afinal o tal trio de intrusos, passou a ser um quarteto a partir de então!"

“Ora então cá vou eu entrar na dança! E começo já com uma 'bomba': Vocês estão à procura do que aconteceu em Paredes de Coura que fez surgir o OUSAM e o Projeto e vão falando nas mudanças no Centro de Saúde e na ligação do Centro de Saúde com as escolas e com as comunidades locais. Tudo isso tem grande importância, mas é preciso olhar para quando é que se sentiu o 'clique' que fez desencadear o movimento imparável da mudança. E a minha ideia é a de que quem representou este 'clique', quem foi o autêntico ponto de partida disto tudo, foi a Fatinha! Muitos de vós talvez não saibam, mas quando vim a Paredes de Coura para passar um mês, no início do ano letivo de $83 / 84$, estes meus três amigos que já falaram, contaram-me as suas preocupações com o facto de haver uma criança, numa das freguesias do concelho, que se recusava terminantemente a ir para a escola e só falava dentro de casa com a família.

Entretanto, pelos contactos já havidos, parecia que esta criança - a Fatinha - não sofria de deficiências e tinha uma relação aparentemente normal com os pais e os irmãos. Assim, os meus amigos propuseram-me que tentasse relacionar-me com a Fatinha e procurasse entender o que se passava e o que poderia fazer-se.Eu estava muito esgotada em Lisboa e tinha ido descansar para Paredes de Coura mas aquele desafio interessou-me. Então, fui algumas tardes falar com a Fatinha, no campo onde ela estava com o gado. Levei plasticinas para os irmãos mais novos também se entreterem e começou por aqui uma brincadeira que rapidamente passou a ser igualmente o mote das conversas que tínhamos à noite, eu e os meus amigos que me tinham feito este desafio. E não tenho dúvidas de que foi a partir da Fatinha e das conversas e reflexões que fomos tendo em relação ao que se passava com ela que foram nascendo as ideias sobre o tipo de projeto a desenvolver.

É verdade que a Fatinha era um caso extremo que nos grita aos ouvidos, mas às vezes é assim que nos tornamos atentos às raízes que podem ser comuns a esta situação e a outras que vamos conhecendo. E lembro-me que esta enfermeira e os dois médicos já então andavam preocupados com o insucesso escolar, e que, à medida que conversávamos entre nós e alguns professores, ou escutávamos famílias com crianças, íamos valorizando o facto de a grande maioria das crianças ir para a escola sem ter passado pelo Jardim de Infância, e que nesse tempo dos três aos cinco anos, muitas vezes, ou iam acompanhar os pais no trabalho do campo ou ficavam fechados em casa parte do dia, as crianças mais velhas cuidando das mais novas, o que tinha sido o caso da Fatinha.

Entretanto, passou-se o mês, voltei para Lisboa e continuei a pensar e a trocar cartas com eles sobre o que condicionava o insucesso escolar naquele concelho, desde a 
dispersão habitacional e o isolamento social, ao analfabetismo de muitos adultos, aos hábitos alcoólicos que se estendiam às próprias crianças, à pouca motivação para que os miúdos frequentassem o Jardim de Infância, a que se associava o ter muitas vezes de se percorrer a pé 2 ou $3 \mathrm{Km}$, etc, etc. e depois, pensávamos como fazer para responder a esta situação, sabendo que não iriam construir-se Jardins de Infância em cada uma das dezoito freguesias que não os tinham e que, mesmo com o Jardim de Infância na sede de freguesia, continuaria a ser preciso uma percentagem grande das crianças andarem $2 \mathrm{ou}$ 3Km para chegar lá.

E todas estas ideias foram prosseguindo até que combinámos que precisávamos de trabalhar juntos para desenhar um projeto e ver da viabilidade da sua concretização. Então, decidi pedir um tempo de licença sem vencimento na instituição onde trabalhava e parti de novo para Paredes de Coura no início de 1985.

O desenho do projeto inicial foi o de constituir uma pequena equipa interdisciplinar que funcionasse como grupo animador com crianças, famílias e respetivas comunidades. Em relação às crianças pensou-se em dois grupos - o das crianças em idade pré-escolar e o daquelas que andavam na primeira fase $\left(1^{\circ}\right.$ e $2^{\circ}$ ano) e não tinham frequentado o Jardim de Infância.

Como o projeto iria iniciar-se em só algumas freguesias, decidiu-se aprofundar quais poderiam ser prioritárias (mais insucesso escolar, mais problemas de isolamento, mais possibilidades de viabilização por motivação local e espaço disponível...). Isto levou-nos a procurar fazer uma primeira colheita de indicadores do insucesso escolar no concelho e por freguesia. Um senhor do grupo dos "mais antigos" interrompe: "Ora aqui está uma ocasião em que posso dar um pequeno contributo...É que, como alguns de vós se lembrarão, eu era então o Delegado Escolar e estivemos juntos a fazer esse levantamento. Até trouxe comigo um papelinho com umas notas, em relação a alguns dados do concelho. Diz assim: " $92 \%$ das crianças que então frequentavam a $2^{\text {a }}$ fase $\left(3^{\circ} \mathrm{e}\right.$ $4^{\circ}$ anos de escolaridade) não tinham frequentado a educação pré-escolar. No ano letivo de $83 / 84,18 \%$ dos alunos da $1^{a}$ fase já estavam nessa fase há quatro ou mais anos, o que correspondia a 106 crianças. No ano letivo de 84/85, 46\% dos alunos matriculados há dois ou mais anos na $1^{a}$ fase não transitou para a $2^{a}$ fase. Tenho ainda um registo de que a taxa de analfabetismo em Paredes de Coura (1981) era de 32\% (no Continente, o valor desta taxa era de $20 \%$ )".

"Muito obrigado". De facto, a sua intervenção veio no momento oportuno e ilustra não só a gravidade do problema, mas também que nessa fase de elaboração do projeto já estávamos a articular-nos com a Delegação Escolar, com os professores, com o Centro de Saúde e outros serviços para conhecer melhor a realidade local. Aliás, foi nesse período que o Centro de Saúde nos alertou para os resultados de um inquérito nacional sobre a alimentação em que o distrito de Viana do Castelo vinha apontado como o distrito do País em que se comia menos fruta, e estava em antepenúltimo lugar no consumo de leite e nós sabíamos que o leite era talvez a maior fonte de rendimento das famílias rurais, através da venda para as viaturas das fábricas que passavam a recolhê-lo.

Por outro lado, e à medida que íamos identificando as freguesias que podiam ser prioritárias, e perante a ideia de se encontrar um espaço da comunidade que pudesse ser usado para atividades regulares com crianças, começámos a contactar as Juntas de Freguesia e os Párocos, para lhes contar sobre o projeto e saber das hipóteses de espaço disponível. Assim íamos avançando à procura duma resposta inovadora que contribuisse para a redução do insucesso escolar através de uma intervenção com as crianças, as 
famílias, as escolas e as comunidades locais, tendo em vista favorecer o desenvolvimento global das crianças de algumas freguesias do concelho".

"Talvez seja agora o momento de dizer que, em Abril de 1985, com o texto do projeto concluído, estávamos perante dois desafios difíceis: - Como conseguir financiamento para o pequeno grupo animador funcionar, para os transportes e para os materiais? - Como desenvolver a conjugação de esforços entre este grupo animador, as famílias e toda a comunidade local, para além dos serviços que já nos apoiavam?"

É verdade que o trabalho comunitário em que já tínhamos estado envolvidos se processava, ou através dos serviços públicos a que estávamos ligados, ou de instituições que já tinham os seus sistemas de funcionamento próprios, com sustentabilidade e uma boa implantação comunitária, mas aquele projeto não poderia ser suportado pelos serviços públicos e não víamos nenhuma instituição interessada...

Quanto ao financiamento, começámos à procura e como não vale a pena referir aqueles que não corresponderam, é rápido resumir o que conseguimos: - um pequeno apoio financeiro, mas dado com muito afeto e solidariedade, pela presidente da UNICEF em Portugal, e uma resposta que permitiu garantir o financiamento essencial do projeto nos primeiros quatro anos, por parte da Fundação Calouste Gulbenkian (Departamento da Educação), que desde o início nos acolheu, escutou, aconselhou e ajudou a operacionalizar o projeto, com pleno respeito pelos princípios e práticas por nós assumidas e sem peias burocráticas.

“Agora, em relação a como conseguimos uma boa implantação comunitária...é praticamente a estória de dois casamentos!”. "Já estou a ver que um desses casamentos é o meu! Não há maneira de se esquecerem dessa parte... Mas não nego que foi quando foram aquelas conversas de preparação para o casamento, com o Pároco de Paredes de Coura, e a propósito da responsabilidade social dos cidadãos e famílias, comecei a magicar que fazia falta no concelho uma associação diferente, que assumisse um papel social sem ser só para dar esmolas aos mais necessitados, e lembrei-me de falar disto com algumas pessoas minhas amigas - eram as tais conversas nos intervalos para café, de que se falou há pouco, na brincadeira - e foi a partir daí que nasceu a ideia do OUSAM - Organismo Utilitário e Social de Apoio Mútuo - que tem um nome a lembrar a sua função social muito prática e de reciprocidade, mas também faz um trocadilho com a palavra "ousadia" de quem tem a coragem de fazer algo diferente, remando contra a maré do "não vale a pena mudar, porque sempre foi assim..." Só que não me lembro de mais ninguém que se tenha casado naquela ocasião..."

"Pois o outro casamento resultou de um "amor à primeira vista" e foi pouco tempo depois dessas vossas conversas no café, a pensar no OUSAM... Explicando melhor, vocês convidaram-me para uma reunião um pouco mais alargada em que quase todos eram courenses - pessoal ligado ao Centro de Saúde e aos Bombeiros, um ou dois professores, alguns familiares e amigos, e penso que eu era o único dos tais intrusos que se iam integrando aos poucos na terra. Apresentaram a ideia de uma nova associação e quando se estava à procura do que se podia fazer que fizesse falta ser feito e em que ninguém tivesse ainda ensaiado iniciativas novas, eu falei no projeto que estava a ser elaborado por aquele pequeno grupo de técnicos da saúde e educação, e na importância que teria aquele projeto ser desenvolvido por uma associação local, pois só assim poderia ser verdadeiramente um projeto comunitário em vez de ser olhado como uma iniciativa de técnicos dos serviços de educação e saúde.

Foi então que se deu o tal amor à primeira vista entre uma associação e um projeto, pois ambos descobriram que cada um só seria feliz com o outro. E diria até que 
a paixão foi tão grande que o Projeto "À descoberta do ser criança no meio rural" passou a ser o centro principal das atividades do OUSAM e que ao falar-se do OUSAM se ia dar quase sempre ao Projeto. "Este foi, portanto o segundo casamento".

"Ora bem. Como já chegámos ao momento em que o OUSAM decidiu ser a associação promotora do Projeto e em que a equipa responsável do mesmo se integrou nesta associação, vale a pena dizer alguma coisa sobre a primeira tentativa experimental de aplicação do Projeto, em Junho de 1985".

"Aqui entro eu como professora de uma das escolas com quem se resolveu ensaiar uma pequena experiência de animação com crianças, aproveitando parte das férias de Verão". Na minha freguesia havia duas escolas primárias, cada uma com um professor. Nós ambos vínhamos conversando já há algum tempo com a equipa que estava a desenhar o projeto, e eu também estava a acompanhar o grupo de pessoas que resolveu avançar com o OUSAM.

Entretanto, a freguesia da minha escola ficou entre as quatro que a equipa considerou serem prioritárias e combinou-se que antes de acabarem as aulas, nós e a educadora da equipa iríamos sensibilizar os alunos e os pais no sentido de as crianças virem regularmente durante as férias até à escola para brincarem juntas com a educadora, e fizemos também o convite para os alunos trazerem os irmãos mais novos que quisessem vir brincar, o que facilitou a motivação dos mais pequenos por estas novas atividades".

"Por esses tempos, a iniciativa constituiu uma boa experiência-piloto para a concretização do projeto, quer em relação às formas de comunicar com os pais, ouvi-los e motivá-los pelas brincadeiras com as crianças, quer em relação às formas de brincar dos miúdos mais pequenos e o que mais gostavam de fazer... E também deu para perceber melhor que, se os mais pequenos precisavam de se socializar e ser estimulados por brincadeiras que favorecessem o seu desenvolvimento global, também as crianças do $1^{\circ}$ e $2^{\circ}$ anos sofriam de forma manifesta dessa falta de estímulos anteriores para o seu desenvolvimento e socialização, pelo que tinha todo o cabimento incentivá-los pela via lúdica a compensar essas carências.

Foi depois disso que se combinou que, a partir do início do ano letivo 85/86, avançar-se-ia em quatro freguesias, escolhendo duas delas para trabalhar duas tardes por semana com crianças da $1^{\mathrm{a}}$ fase do $1^{\circ}$ ciclo, após o tempo da escola, enquanto que nas outras duas freguesias as atividades seriam em duas manhãs por semana, com grupos de crianças que ainda não andassem na escola.

Foi também então que se percebeu não ser viável contar-se com a deslocação a pé das crianças com menos de seis anos ao longo de 1,2 ou3 quilometros até ao espaço das atividades, além de que o pequeno carro que a Fundação Gulbenkian nos tinha cedido teria de fazer várias viagens para proceder ao transporte dos miúdos entre o tal espaço e as suas casas.

Mas face a cada desafio ia-se descobrindo uma resposta. Em relação ao espaço das atividades, podia ser uma sala no edifício da Junta de Freguesia ou uma sacristia duma igreja...Quanto ao transporte, passou a ser uma daquelas carrinhas de nove lugares que alguém pôs à disposição e vários de nós conduzíamos. E em relação aos contactos com pais e avós, nunca tínhamos imaginado como esta sucessão de pequenos momentos com eles a propósito de irmos buscar e trazer as crianças era a chave para uma relação de proximidade em que o à vontade, as cumplicidades e a amizade iam crescendo. Por isso foi tão fácil a adesão das famílias quando quisemos integrar no 
projeto encontros periódicos em que se lhes mostrava o que as crianças iam fazendo, se propunha aos pais e avós que tentassem também fazer bonecos com massapão ou pinturas com aguarelas, ou jogar alguns dos jogos de que as crianças gostavam mais.

E isto tudo já tem a ver com o Projeto a funcionar em pleno, após aquela experiência-piloto, na parte inicial das férias.É que entretanto, já com o financiamento da Fundação Gulbenkian, foi possível que uma técnica de serviço social se viesse juntar à equipa.

"Sou eu! Ou melhor, fui eu que cheguei em Agosto de 1985 e comecei logo a participar com a educadora nos passos necessários para que o Projeto arrancasse no início do ano letivo - conseguir um espaço da comunidade em cada uma das quatro freguesias, divulgar o Projeto, visitar cada família com crianças para as convidar e para explicar o funcionamento do Projeto, arranjar materiais, etc, etc.Havia aquela sensação extraordinária de se estar a construir coisas pela primeira vez, mas tudo brotava de uma maneira simples, natural, e à medida que o Projeto começou a reforçar a interação com as famílias, estas foram aderindo e passaram a sentir-se por dentro dele.”

"Aliás, as famílias também aderiram porque o Projeto deu espaço aos mais velhos para explicarem o significado de tudo o que se fazia. E os mais novos interessavam-se por ouvi-los e assim começavam a aprender o sentido das coisas.Este espaço dado aos mais velhos para terem um papel educativo foi acontecendo a propósito das novidades que as crianças contavam e que levavam a combinar com elas e com as famílias, por exemplo, uma manhã a visitar a tia Alzira quando ela fosse ordenhar as duas vacas, ou ir ver os pintainhos da galinha "pintada" que tinham nascido ontem, ou ainda para acompanhar uma família a tirar batatas da terra, a colher uvas ou a fazer uma sementeira. O curioso é que, embora estes acontecimentos fizessem parte do quotidiano, eram vistos pelas crianças com um olhar novo, fazendo perguntas, ouvindo explicações dos mais velhos, e tomando consciência das relações entre o trabalho com as plantas e com os animais e a nossa alimentação. Tudo isto, afinal, ia contribuindo para o desenvolvimento global das crianças, a par das brincadeiras, dos jogos, das pinturas, das palavras trocadas, das regras aprendidas e dos afetos partilhados."

"E ainda falámos muito pouco de como esta relação com as famílias se estendeu facilmente às pequenas comunidades dos lugares onde elas viviam (aliás, neste concelho, é difícil falar de aldeias; o que há é muitos lugares, às vezes com meia dúzia de casas, e até a sede da freguesia pode ser apenas uma associação de lugares próximos com uma igreja ali no meio, uma casa para a Junta de Freguesia e uma escola perto).Ora, se nestas pequenas comunidades era natural que todos ficassem a conhecer as carrinhas e as novas atividades com as crianças, também foi espontâneo $o$ envolvimento quando se promoveram pequenas festas comunitárias, sobretudo aquelas que vieram revitalizar valores antigos que estavam a cair em desuso - "mascaradas pelo Carnaval", comemoração do dia de Reis, magusto...E isto porque, mais uma vez, se partiu das memórias dos mais velhos e se abriu o espaço a todos os que quiseram participar.Por outro lado, procurou-se que as crianças fossem alargando os seus horizontes de conhecimentos para além do lugar onde viviam, e começaram a fazer-se encontros intergrupos bem como visitas a locais interessantes - idas à praia, visita à Biblioteca Municipal, contacto com artesãos, piqueniques em parques naturais, etc."

"Bem, vou dar aqui uma achega, juntando o ponto de vista dos professores locais que mais participaram no Projeto, acrescido ainda do facto de mais tarde eu ter assumido funções diretivas no OUSAM". Ora, no caso das atividades com crianças do $1^{\circ}$ e $2^{\circ}$ anos, foi muito importante o esforço feito no sentido de se irem articulando, quer 
as atividades de rotina, quer as iniciativas com maior mobilização comunitária, com os professores daquelas escolas e com o seu plano de trabalho, o que constituiu também um desafio às escolas para se abrirem mais à comunicação com a comunidade envolvente.

Isso foi mais longe a partir do ano letivo de 86/87 em que a equipa técnica do Projeto passou a ter não uma mas duas educadoras de infância, além da técnica de serviço social, e que, nas quatro freguesias abrangidas, passaram a ser envolvidos os dois grupos de crianças - grupo em idade pré-escolar e grupo de crianças do $1^{\circ}$ e $2^{\circ}$ anos - duas vezes por semana com cada grupo.

Foi também em 86/87 que se estruturou a equipa coordenadora do Projeto de forma claramente interdisciplinar e interinstitucional, passando a integrar um representante da direção do OUSAM, um médico e uma enfermeira do Centro de Saúde, dois professores do primeiro ciclo ligados às freguesias abrangidas, além das duas educadoras e da técnica de serviço social que compunham a equipa técnica do Projeto.”

"E é verdade que, se até esse momento o Centro de Saúde já vinha colaborando por várias formas com o Projeto, através da Equipa Coordenadora foi possível ir mais longe, em articulação mais estreita com as escolas e com as atividades de saúde escolar, nomeadamente em relação à educação alimentar, prevenção do alcoolismo, higiene pessoal e outras áreas da educação para a saúde.”

"Ainda nesse ano letivo, começou-se a ensaiar o envolvimento de alguns jovens das freguesias nestes processos de animação. Íamos abrindo caminho, mas também íamos tomando consciência de que havia resistências da parte de alguns professores, apesar das nossas tentativas de articulação... e até do próprio Ministério da Educação que, mais tarde, veio a valorizar o nosso trabalho, mas nessa fase inicial não nos quis apoiar..."

"Esta sucessão de passos que" foram sendo dados veio a culminar no mês de Maio de 1987, em que se procedeu a nova avaliação do Projeto e sua reformulação, passando a designar-se desde então "Á descoberta do ser criança, construindo a comunidade, no Meio Rural".

Vou ler-vos um extrato do texto do Projeto então reformulado que me parece sintetizar bem esta evolução: "Esta equipa partiu da identificação do problema do Insucesso Escolar para um trabalho que fundamentalmente desenvolvia atividades com crianças, trabalho esse com caráter não institucional. Na evolução deste trabalho constatámos que era necessário alargar o âmbito da nossa área de intervenção, o que deu origem a que entre o $1^{\circ}$ e $2^{\circ}$ ano tivéssemos reforçado os nossos objetivos, os quais apontaram para a necessidade de uma maior intervenção junto dos vários setores da Comunidade. Deste modo o $2^{\circ}$ ano de intervenção foi já uma tentativa de maior ligação à Comunidade, tendo, no entanto,como pólo dinamizador das ações, a criança nas suas várias vertentes. É portanto tendo em conta a experiência já adquirida que decidimos formular este novo Projeto. (...)As atividades levadas a efeito fizeram-nos concluir que o verdadeiro problema não será o Insucesso Escolar mas as carências de desenvolvimento da criança que estão diretamente relacionadas com o deficiente desenvolvimento das potencialidades da Comunidade. Desta forma optámos, em termos de estratégia, por considerar a criança como pólo dinamizador das ações a desenvolver na Comunidade".

E já agora salto para um pequeno extrato do Relatório de Avaliação Global, em Julho/89, que completa a ideia do texto anterior: "Se os objetivos deste Projeto se 
centravam na criança, a sua progressiva concretização levou à perceção das muitas potencialidades da interação Família/Escola/Comunidade como condicionantes não só do processo de desenvolvimento infantil mas também do próprio processo de desenvolvimento comunitário".

O ano de 1987 foi portanto um ano de reformulações que representou um passo em frente fundamental.No entanto, este passo em frente mais uma vez surgiu como sendo a evolução lógica duma construção progressiva. E entretanto o Projeto já vinha sendo conhecido e debatido fora do concelho. Em fins de 86, a Fundação Gulbenkian, juntamente com a Fundação Aga Khan decidiram impulsionar a cooperação entre Serviços para a Infância através da Metodologia de Projetos, reunindo num Seminário técnicos de Saúde, Educação e da área Social. O modelo formativo partiu da caraterização de um concelho como desafio para a identificação de problemas e formulação de projetos. Não foi por acaso que o concelho escolhido foi o de Paredes de Coura, em relação ao qual já então se dispunha de um conjunto grande de elementos para um diagnóstico do concelho em diversas vertentes, além da monitorização da evolução de alguns indicadores, sobretudo nas áreas da educação e da saúde. E também não terá sido por coincidência que a Fundação Aga Khan se tenha então disponibilizado para apoiar o Projeto entre 1987 e 1991.

É também o momento de dizer que os dois médicos envolvidos neste Projeto saíram de Paredes de Coura no verão de 1987, sabendo que toda a dinâmica então em curso iria prosseguir, porque localmente o Projeto tinha sido assumido por um bom punhado de pessoas."

"Quando vocês dois saíram, julgo que muita gente pensou que o Projeto já não iria ter continuidade. A seguir, em fins de 1988, saiu de Paredes de Coura a Educadora de Infância que tinha primeiro idealizado as bases a partir das quais o Projeto se desenvolveu e deve ter havido ainda gente a interrogar-se sobre se o Projeto conseguiria manter-se. Mas o Projeto prosseguiu.

Depois, em 1989, eu também deixei Paredes de Coura, e não tinha dúvidas que o Projeto estava plenamente capaz de ser sustentado por quem ficava no OUSAM. Até talvez seja importante que os animadores exógenos saiam para tornar claro a toda a gente, e a eles próprios, que os animadores endógenos e as próprias comunidades têm a capacidade para prosseguir com os processos iniciados, na medida em que tenham podido apropriar-se deles, sentindo-os como seus.

É certo que, como já foi dito antes, havia dificuldades e resistências que criavam tensões, como veio a acontecer no período em que surgiu o Programa Interministerial para a Promoção do Sucesso Educativo (PIPSE), com cujas equipas concelhia e distrital não conseguimos articular, pois, apesar de trabalharmos para o mesmo fim, a nossa lógica era informal, comunitária e participativa e o PIPSE apresentou-se com uma lógica institucional e normativa - queria que saíssemos das freguesias onde o PIPSE interviesse... Mas hoje quase diria que sem estas tensões talvez o Projeto não tivesse avançado, apesar de todo o mal-estar e sofrimento que causaram. Afinal,as mudanças implicam sempre tensões!

É claro que o Projeto se foi modificando e se institucionalizou progressivamente, a partir de 1989. No entanto, nesse processo não perdeu os seus princípios essenciais, e as formas de institucionalização que se foram encontrando com os Ministérios da Educação e da Segurança Social vieram a exprimir o reconhecimento do valor das atividades desenvolvidas pelo Projeto, justificando o garantir-lhes a sua futura sustentabilidade." 
"No ano letivo 88/89 estava eu a coordenar a equipa técnica, já então abrangendo oito freguesias e havendo pela primeira vez o destacamento de um professor e duas educadoras e infância por parte do Ministério da Educação, ao mesmo tempo que o Ministério do Emprego e da Segurança Social também começou a apoiar o Projeto através de um acordo atípico. Em 89, a Gulbenkian concluiu o seu apoio, uma vez que tinha sido planeado para os quatro primeiros anos.

Para mim, considero que houve um "ciclo do Projeto" entre 1985 e 1991, com uma primeira fase $(85$ - 89), em que o apoio de suporte veio da Gulbenkian, e correspondeu ao desenvolvimento de iniciativas de base comunitária, num modelo informal, em que as crianças eram desafiadas a aprender e a desenvolver-se a partir do que acontecia nas suas vidas, em relação com os companheiros, as famílias e as comunidades. Não era um "ensino em sala fechada", as crianças e os técnicos "corriam por gosto e não se cansavam"... Havia um pequeno Boletim onde se iam registando os acontecimentos. Chamava-se "B - A - BÁ da Descoberta" e o termo "descoberta" é bem uma palavra - chave dessa primeira fase, que leva à descoberta de que há uma relação recíproca entre o desenvolvimento das crianças e o desenvolvimento da comunidade onde vivem, o que quer dizer que as próprias crianças podem ter um papel animador em relação ao desenvolvimento comunitário.

A segunda fase, entre 1989 e 1991, foi uma fase de passagem, de sustentação, de institucionalização do Projeto - passou-se então de uma atividade experimental, militante, centrada no "fazer diferente", para uma atividade continuada, estruturada, em que a Segurança Social começou a intervir na forma como os serviços eram prestados, embora ainda houvesse financiamento da Aga Khan, que apoiou então a criação de uma Ludoteca e a manutenção de atividades comunitárias.

Quero ainda dizer que em 89, na transição entre a primeira e a segunda fase do "Ciclo do Projeto", e, sobretudo quando se debateu sobre o rumo a tomar, surgiram claramente duas vias - este caminho da "instituicionalização" com apoio ministerial e o caminho de um "projeto de desenvolvimento integrado", tendo sido equacionada a possibilidade de ele ser apoiado pela autarquia. Mas a autarquia não estava ainda muito sensibilizada para assumir um papel ativo neste tipo de iniciativas e eu próprio acabei por considerar que não tínhamos condições naquele momento para investir num projeto de desenvolvimento integrado que podia ser uma daquelas aventuras que acabam mal...De qualquer modo, mesmo tendo-se escolhido o caminho mais prudente - do acordo atípico e do destacamento das duas educadoras e de um professor - os anos de 1992/94 foram muito difíceis porque o Ministério da Educação não quis continuar a pagar os destacamentos, a Aga Khan terminou o seu apoio e a verba da Segurança Social sozinha era muito escassa.

Finalmente, em 1995, o OUSAM e a Segurança Social chegaram a acordo e negociaram o prosseguimento das atividades dentro dos estatutos de ATL e de educação pré-escolar, em termos bastantes mais vantajosos sob o ponto de vista financeiro, mas mais "formatados" segundo o modo institucional do "trabalho em sala". A partir de 1997, este processo foi alargado para um acordo tripartido OUSAM/Ministério da Educação/Ministério do Trabalho e Solidariedade, correspondente à criação de cinco Jardins de Infância e onze ATL.

Porém, apesar de tudo, os tais genes que havia no nosso ADN continuaram a manter abertas algumas pontes para a intervenção comunitária e para os contactos com as famílias, não só através da "volta das carrinhas", mas também porque, entretanto o "OUSAM começou a apoiar a população idosa em algumas freguesias, passou a 
acompanhar os beneficiários do RSI, através de contratualização com a Segurança Social, e mantém vivo o gosto pela comunicação com famílias e comunidades".

“Apresento-me”. Sou também professor, mas universitário. Entretanto, desde os anos noventa fui acompanhando experiências educativas, comunitárias e de desenvolvimento local no concelho de Paredes de Coura. Cheguei um pouco tarde e não pude acompanhar diretamente os primeiros anos do OUSAM e do Projeto "À descoberta do ser criança no meio rural", mas procurei compensar isso registando os testemunhos de vários dos principais intervenientes e lendo os documentos produzidos no âmbito do Projeto. Dediquei-me também a estudar o processo que levou ao encerramento das escolas do primeiro ciclo em todo o concelho e à criação de uma única Escola Básica Integrada (EBI) na vila de Paredes de Coura.

Quero dizer-vos também que foi muito interessante ouvir as vossas intervenções, pois elas vieram dar mais vida a muitas ideias lidas e palavras registadas ao longo do meu trabalho. Por outro lado, sendo eu um interveniente interessado em todos estes assuntos, embora exterior em relação ao que se passou de facto no OUSAM e no Projeto, penso que posso juntar aqui alguns contributos, relacionando coisas e levantando questões, sem outra pretensão que não seja o partilhar os meus pensamentos convosco, consciente que a visão de cada um de nós é parcelar, incompleta e agora também mais enviesada à medida que aquele tempo presente se torna passado e que procuramos analisá-lo à luz das ideias e do contexto em que vivemos hoje. No meu caso, este enviesamento será ainda maior porque recolhi testemunhos duma realidade que já foi lida e traduzida por aqueles com quem falei. Por tudo isto, limito-me, como disse, a pensar alto e fazer perguntas, desejando que isso ajude a relacionar factos e a clarificar o sentido das coisas.

Como a manhã está a chegar ao fim e vamos retomar a conversa após o almoço, pensei que seria bom intervir agora para deixar no ar as tais questões em que fui pensando, porque pode ser que alguns de vós queiram aproveitá-las como ponto de partida para outros contributos, talvez outras perguntas, talvez tentativas de resposta, talvez outras ideias... e possamos partir disso a seguir ao almoço.

Então aqui vão as minhas reflexões e questões:

1) Uma das coisas que me atrai no OUSAM e no Projeto "À descoberta do ser criança no meio rural" é de facto a forma como aconteceu o seu início e como se desenvolveu. Isso foi aqui narrado com alguns detalhes e conjugando diversas perspetivas que convergiram para iniciativas conjuntas. Foram referidos alguns acontecimentos que concorreram para o arranque do Projeto e para a criação do OUSAM. Foram referidas pessoas - chave nesse processo. Podemos discutir sobre o peso relativo que esses acontecimentos e essas pessoas tiveram na origem do OUSAM e do Projeto. No entanto interessa - me também que nos questionemos sobre que palavras - chave exprimem melhor as forças que geraram este movimento. Serão várias, decerto. Mas vale a pena procurar identificá-las e partilhá-las entre nós.

2) Penso que é interessante registar o facto de o Insucesso Escolar não ter sido identificado como problema relacionável com a saúde naquele processo de planeamento participado que o Centro de Saúde promoveu e no qual os professores tomaram parte. E, contudo, quando o Delegado Escolar revelou alguns dados estatísticos sobre aproveitamento escolar, a gravidade da situação ficou claramente evidenciada. Também é curioso que o Projeto "Ả descoberta do ser criança no meio rural" se iniciou tendo como subtítulo - "contributo para a redução do insucesso escolar", e que a caminhada de dois anos de realização do Projeto levou os seus promotores a reformulá-lo para o 
título "À descoberta do ser criança, construindo a comunidade, no meio rural", ao mesmo tempo que, naqueles dois extratos lidos pelo médico M2, assumem "ter concluído que o verdadeiro problema não será o Insucesso Escolar mas as carências de desenvolvimento da criança que estão diretamente relacionadas com o deficiente desenvolvimento das potencialidades da comunidade", o que me parece ser complementar do que, duas intervenções a seguir, o professor diz a propósito do termo "descoberta", enquanto palavra-chave da primeira fase do Projeto, a qual "leva à descoberta de que há uma relação recíproca entre o desenvolvimento das crianças e o desenvolvimento da comunidade onde vivem, o que quer dizer que as próprias crianças podem ter um papel animador em relação ao desenvolvimento comunitário". Por fim, um pouco depois o mesmo professor refere a sua hesitação entre a via da "institucionalização progressiva do Projeto" e a via do seu prosseguimento como Projeto de Desenvolvimento Integrado, indicando as razões pelas quais se optou pela primeira via.

A minha questão tem, portanto a ver com esta relação recíproca entre o desenvolvimento das crianças e o desenvolvimento das comunidades/desenvolvimento local, e o papel que a saúde e a educação têm nesses processos. Em termos práticos isto pode projetar-se, por exemplo, na questão sobre como pode um projeto de desenvolvimento local, abrangendo uma ou várias pequenas comunidades rurais, relacionar-se com o papel educativo das respetivas famílias, com o papel educativo das respetivas escolas e com a participação cidadã das respetivas comunidades? E pronto. Já temos aqui dois bons pontos de partida para o debate depois de devorarmos o nosso Bacalhau à Miquelina. É natural que haja outras questões, outras memórias do passado e decerto também muitas tentativas de resposta com pistas para o futuro. Até já!

\title{
CONSIDERAÇÕES FINAIS
}

Por motivos alheios à nossa vontade, não foi possível prosseguir com a gravação desta sessão no período da tarde, nem foi distribuído nenhum comunicado com quaisquer conclusões. Pede-se aos interessados para imaginarem o que pode ter sido o debate entre as diversas personagens presentes na sala, algumas das quais intervieram no período da manhã. Também se sugere que as pessoas e grupos mais interessados no debate sobre o OUSAM e o Projeto ou sobre as questões levantadas ao final, entrem na sala, mesmo que esta agora esteja vazia e avancem com o debate como entenderem.

\author{
Façam favor. \\ Para abrir a porta da sala, não clique $A Q U I$ porque não acontece nada. \\ Faça você mesmo a sala onde quiser. \\ Ladeira, 12 de Outubro de 2012
}

\section{REFERENCIAS}

BAKHTIN, M. Para uma filosofia do ato responsável. São Carlos: Pedro e João Editores, 2012.

FERREIRA, F. I.O Estudo do Local em Educação - dinâmicas socioeducativas em Paredes de Coura. Instituto de Estudos da Criança, Universidade do Minho: Braga, 2003.

FERREIRA, A. C. Organização da Assistência à Criança - perspetiva do médico de Saúde Pública num Centro de Saúde Rural. In JUVENIL: Boletim do serviço de Pediatria do Hospital Distrital de Viana do Castelo, n²2, 1986. 
FERREIRA, A. C. Planeamento em Saúde. Ensaio de sistematização de uma experiência em curso. In: Boletim de Educação Sanitária, v. VII, n. 1, 1984.

FREIRE, P. Educação como prática de liberdade. Rio de Janeiro: Paz e Terra, 1967.

FREIRE, P. Pedagogia do Oprimido. 2 ed. Porto. Editora Afrontamento, 1975.

GOMES, L. C. Animação, palavra - chave. Edições GAF - Grupo Aprender em Festa. Gouveia, 2000.

\section{FONTES DOCUMENTAIS}

ASSOCIAÇÃO OUSAM - Estatutos da Associação e toda a documentação referente ao Projeto "À descoberta do ser criança no meio rural" e ao Projeto "À descoberta do ser criança, construindo a comunidade no meio rural” (1985/1992) -Documentos não publicados. Paredes de Coura.

CENTRO DE SAÚDE DE PAREDES DE COURA - Documentos referentes aos Planos de Atividades de 1984, 1985, 1986 e 1987.-Documentos não publicados. Paredes de Coura.

FUNDAÇÃO AGA KHAN/FUNDAÇÃO CALOUSTE GULBENKIAN (1988) Integração de Serviços para a Infância. Metodologia de Projetos. Seminário. Lisboa: Fundação Aga Khan/Fundação Calouste Gulbenkian.

Recebido: $10 / 04 / 2020$

Aprovado: 12/06/2020 